\title{
Transaldolase deficiency
}

INSERM

\section{Source}

INSERM. (1999). Orphanet: an online rare disease and orphan drug data base.

Transaldolase deficiency. ORPHA:101028

Transaldolase deficiency is an inborn error of the pentose phosphate pathway that presents in the neonatal or antenatal period with hydrops fetalis, hepatosplenomegaly, hepatic dysfunction, thrombocytopenia, anemia, and renal and cardiac abnormalities. 